\title{
Solvent-Dependent Deprotonation of meso-Pyrimidinylcorroles: Absorption and Fluorescence Studies
}

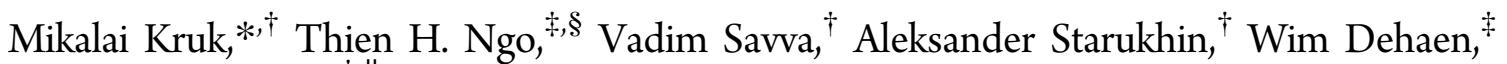 \\ and Wouter Maes* $*$,
${ }^{\dagger}$ B. I. Stepanov Institute of Physics of National Academy of Sciences, Pr. Nezavisimosti 68, Minsk 220072, Belarus
${ }^{\ddagger}$ Molecular Design and Synthesis, Department of Chemistry, KU Leuven, Celestijnenlaan 200F, B-3001 Leuven, Belgium
${ }^{\S}$ Institut für Chemie und Biochemie-Organische Chemie, Freie Universität Berlin, Takustrasse 3, D-14195 Berlin, Germany
"Design \& Synthesis of Organic Semiconductors (DSOS), Institute for Materials Research (IMO-IMOMEC), Hasselt University, Universitaire Campus, Agoralaan 1, Building D, B-3590 Diepenbeek, Belgium

ABSTRACT: The absorption spectra of 10-(4,6-dichloropyrimidin-5-yl)-5,15dimesitylcorrole have been studied in 15 solvents. The formation of deprotonated corrole species was found to account for the dramatic changes in the absorption spectra in several solvents. Careful analysis of the relationship between the formation of deprotonated species and solvent properties results in the conclusion that there is no single solvent parameter correlation, and either multiparameter correlations or specific solute-solvent interactions (preferential solvation of the most acidic $\mathrm{NH}$ tautomer or perturbation of intramolecular hydrogen bonding in the macrocycle core) should be considered. The fluorescence properties of the deprotonated pyrimidinylcorrole are also reported for the first time and compared to those of free-base and protonated species.

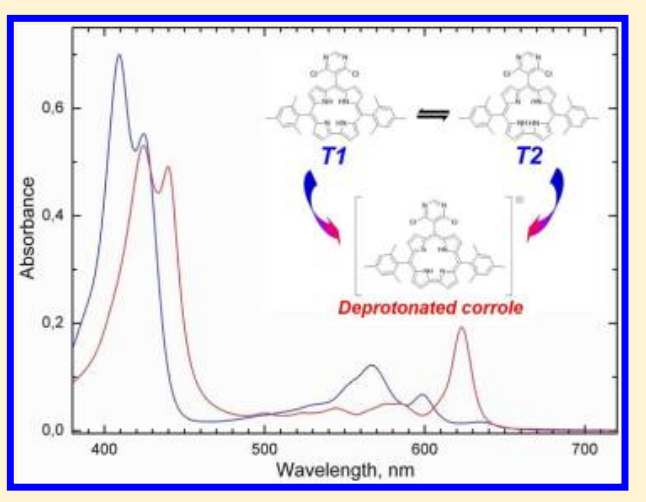

\section{INTRODUCTION}

Corroles, contracted porphyrin analogues lacking one mesocarbon bridge, have attracted considerable attention as they have the potential to add some peculiar features to the traditional porphyrin properties. Corrole-based materials are nowadays extensively studied and applied as novel (oxidation) catalysts, antitumor treatment, and imaging agents as well as active materials in the design of new sensors and optoelectronic devices. ${ }^{1,2}$ Starting from the very first publications on corrole synthesis in the middle of the sixties, ${ }^{3}$ it was noticed that their ground state absorption spectra undergo dramatic changes as a function of solvent. After the discovery of effective methods for the synthesis of (more stable) triarylcorroles, ${ }^{4}$ a large number of new derivatives have been investigated in following studies, and the observation has been made that high sensitivity of the ground state absorption spectra of corroles to the solvent employed is a quite general feature for all types of corroles. The first attempt toward rationalization of the observed changes in the ground state absorption spectra of triarylcorroles has been made by Ziegler et al. ${ }^{5}$ Three main possible contributions have been pointed out on the basis of the analysis of available experimental data. First of all, NH tautomerization, due to the asymmetry of the tetrapyrrolic corrole macrocycle (one direct $\mathrm{C}_{\alpha}-\mathrm{C}_{\alpha}$ dipyrrole linkage instead of the methine $\mathrm{C}_{\alpha}-\mathrm{C}_{m}-\mathrm{C}_{\alpha}$ bridge) resulting in two different positions of the three protons in the core of a free-base $(\mathrm{Fb})$ corrole, might have an effect. The second potential factor that could affect the spectra is deprotonation of the corrole macrocycle in polar solvents, due to the substantially higher $\mathrm{NH}$ acidity of the pyrrolic nitrogen atoms in corroles as compared to porphyrins and other related macrocycles. ${ }^{6}$ Finally, it was proposed that the solvent dependent spectral changes could be due to hydrogen bonding of the solvent molecules with an internal $\mathrm{NH}$ group of the corrole. Ziegler and co-workers inclined to the third explanation, ${ }^{5}$ but neither direct data supporting it nor indisputable arguments excluding the first two possibilities were presented.

Our recent findings have indicated that the two $\mathrm{NH}$ tautomers of meso-pyrimidinyl-substituted triarylcorroles coexist in fluid solution at room temperature, and each of the tautomers has its own distinct ground state absorption spectrum. ${ }^{7}$ This coexistence leads to two different rates of macrocycle protonation since the $\mathrm{p} K_{\mathrm{a}}$ values of the two $\mathrm{NH}$ tautomers are substantially different. ${ }^{7}$ However, it has been observed that not all of the solvent-induced effects can be explained on this basis, but there are at least two factors that contribute to this phenomenon simultaneously. The second contributing factor is the acid-base equilibrium between the $\mathrm{Fb}$ and deprotonated corrole structures.

In the pioneering paper of Johnson and Kay, easy deprotonation of an octa- $\beta$-alkylated corrole derivative has been reported with one drop of $1 \% \mathrm{NaOH}$ in DMF solution. ${ }^{3}$

Received: May 31, 2012

Revised: $\quad$ August 24, 2012

Published: September 17, 2012 
Much later, a few reports on the absorption spectra of deprotonated triarylcorroles have been published. ${ }^{8}$ It was shown that the deprotonated form of tris(pentafluorophenyl)corrole is formed upon addition of a small amount of organic base $\left(\mathrm{Et}_{3} \mathrm{~N}\right){ }^{8 \mathrm{a}}$ The measured spectrum showed the same main features as that reported by Johnson and Kay. The same kind of absorption spectrum has also been obtained for triphenylcorrole in DMF, without any base being been added. ${ }^{8 \mathrm{~b}}$ The authors concluded that triaryl-substitution leads to a pronounced increase in the acidity of the $\mathrm{NH}$ pyrrole nitrogen atoms as compared to that for octa- $\beta$-alkylcorroles. A similar absorption spectrum has also been observed for tris(heptafluoropentyl)corrole upon the addition of a small amount of triethylamine. ${ }^{8 c}$ The fluorescence spectra of several deprotonated corrole derivatives have also been reported. ${ }^{9}$ Later on, the deprotonation equilibrium has been studied for a water-soluble triarylcorrole derivative (2,7-disulphonato-tris(pentafluorophenyl)corrole) and an attempt to explain the unusually high acidity of corroles has been made. ${ }^{6}$ The spectra reported for the deprotonated water-soluble derivative fit well with those measured for deprotonated corroles in organic solvents. The most recent contribution to the study of deprotonated corrole species has been made by Kadish et al., ${ }^{10}$ who reported on the electrochemistry and absorption spectra for a large group of triarylcorroles with different substitution patterns, including both sterically hindered and unhindered aryl groups at the meso $(5,10$, and 15$)$ positions of the macrocycle. However, spectrophotometric titration data were reported for $\mathrm{Fb}$ octa- $\beta$-ethylcorrole, and the spectra of its protonated and deprotonated forms were also presented. ${ }^{10 \mathrm{c}}$ It was noticed that the spectral features of both protonated and deprotonated species were simultaneously observed in some solvents.

On the basis of the (scattered) results listed above and our own recent findings concerning the $\mathrm{NH}$ tautomers of $\mathrm{Fb}$ pyrimidinylcorroles, the features of the absorption spectra for deprotonated corrole species can be generalized. The long wavelength $0-0$ transition band lies in-between those for the 0-0 transitions of the long-wavelength and short-wavelength $\mathrm{NH}$ tautomers, and the intensity of this band is noticeably higher. At the same time, the Soret band of the deprotonated corrole species undergoes a bathochromic shift as compared to the $\mathrm{Fb}$ corrole.

Detailed analysis of previously obtained ground state absorption spectra for a large family of meso-pyrimidinylcorroles (with $\mathrm{AB}_{2}, \mathrm{~A}_{2} \mathrm{~B}$, or $\mathrm{A}_{3}$-type substitution pattern), ${ }^{11}$ led us to believe that the free-base $\leftrightarrows$ deprotonated corrole equilibrium is likely to intervene for meso-pyrimidinylcorroles as well. For this reason, we have now carefully studied the solvent dependence and the influence of the $\mathrm{Fb} \leftrightarrows$ deprotonated corrole equilibrium on the absorption and fluorescence spectra of a particular $\mathrm{AB}_{2}$-meso-pyrimidinylcorrole (Figure 1). Distinct spectral features of the deprotonated species were revealed and are described in detail. Possible mechanisms to explain the relationship between the solvent properties and the macrocycle protonation state are proposed.

\section{EXPERIMENTAL AND THEORETICAL METHODS}

10-(4,6-Dichloropyrimidin-5-yl)-5,15-dimesitylcorrole $\left(\mathrm{H}_{3} \mathrm{AB}_{2}\right.$; see Figure 1) was prepared in accordance with a previously published synthetic procedure. ${ }^{11 a}$ All solvents were of spectroscopic grade (Sigma-Aldrich, Merck, Acros Organics) and were used as received. UV-vis spectra were taken with a

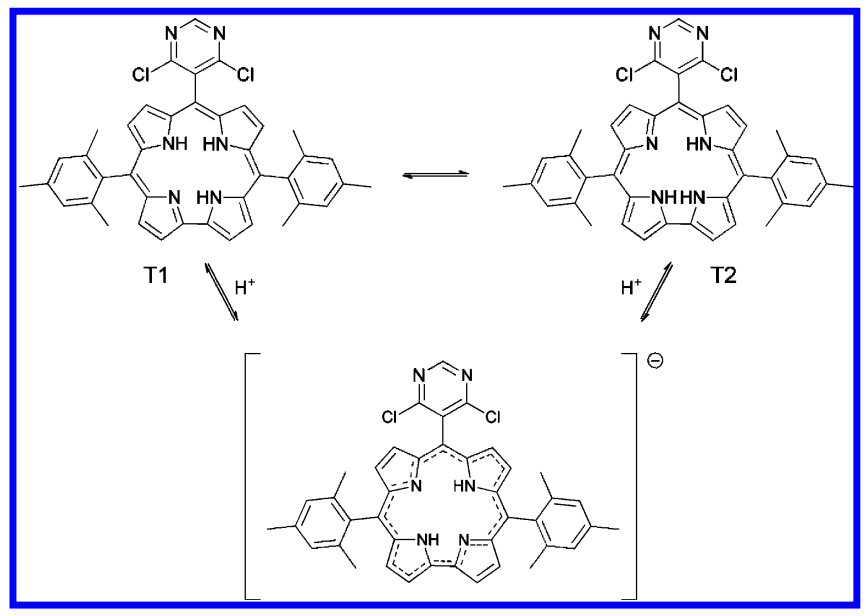

Figure 1. Equilibrium showing the two $\mathrm{NH}$ tautomers of 10-(4,6dichloropyrimidin-5-yl)-5,15-dimesitylcorrole ( $\mathrm{T} 1$ and $\mathrm{T} 2$ are tentatively assigned) and the deprotonated species.

Varian CARY 500 Scan spectrophotometer. The fluorescence measurements were done in standard quartz rectangular cells (1 $\times 1 \mathrm{~cm}$, Hellma) in air equilibrated solutions at $293 \pm 2 \mathrm{~K}$. Deoxygenated solutions were used for the measurements of the fluorescence quantum yields. Deoxygenation of the solutions was performed by Ar bubbling during $20 \mathrm{~min}$ just before the measurements. The fluorescence spectra and fluorescence excitation spectra were measured with the use of a spectrofluorometer SFL-1211 (Solar, Belarus). The fluorescence decay kinetics were measured with the use of a photon counting system FLA-900 (Edinburgh Instruments, UK). The fluorescence quantum yields $\Phi_{\mathrm{fl}}$ were determined using the standard sample method, with $\mathrm{Fb} 5,10,15,20$-tetraphenylporphyrin (TPP) as a reference $\left(\Phi_{\mathrm{fl}}^{0}=0.09^{12}\right)$.

Corrole concentrations were measured spectrophotometrically by means of preliminarily determined extinction coefficients at $298 \mathrm{~K}: \lambda_{\max } / \mathrm{nm} 410\left(\log \varepsilon / \mathrm{dm}^{3} \mathrm{~mol}^{-1} \mathrm{~cm}^{-1}\right.$ 5.02), 427 (4.92), 570 (4.30), 599 (4.05), and 635 (3.28) for $\mathrm{H}_{3} \mathrm{AB}_{2}$ in $\mathrm{EtOH}^{7}$ and 424 (4.98), 440 (4.94), 544 (3.87), 576 (3.96), 584 (3.94), and 623 (4.53) for $\mathrm{H}_{2} \mathrm{AB}_{2}{ }^{-}$in $\mathrm{MeCN}$. No sign of aggregation was found for a corrole concentration range up to $6.0 \times 10^{-5} \mathrm{M}$, wherein all experiments were carried out for both $\mathrm{Fb}$ and deprotonated species.

\section{RESULTS AND DISCUSSION}

Absorption Spectra of the Deprotonated Pyrimidinylcorrole. We have previously reported that the ground state absorption spectra of $\mathrm{AB}_{2}$-type meso-pyrimidinylcorroles differ dramatically upon going from acetonitrile $(\mathrm{MeCN})$ to ethanol $(\mathrm{EtOH})$ and dichloromethane (DCM). ${ }^{11 \mathrm{c}}$ Mixed solvent titration is an effective tool to distinguish between solvatochromic effects and spectral changes arising from chemical alterations in the dissolved compound. The absorption spectra of 10-(4,6-dichloropyrimidin-5-yl)-5,15-dimesitylcorrole in $\mathrm{EtOH} / \mathrm{MeCN}$ mixed solutions are shown in Figure 2. This couple of solvents has been chosen since $\mathrm{EtOH}$ and $\mathrm{MeCN}$ are miscible in any proportion, and the corrole has a good solubility in both of them. Thus, in the mixed solvent, the bulk properties of the solution gradually change from one extreme to another, and the gradual changes in the absorption spectra (mainly the shifts) are characteristic for solvatochromic effects. As a rule, no isosbestic points are observed in such a case. On the contrary, if the dissolved molecule adopts different structural forms (in the 


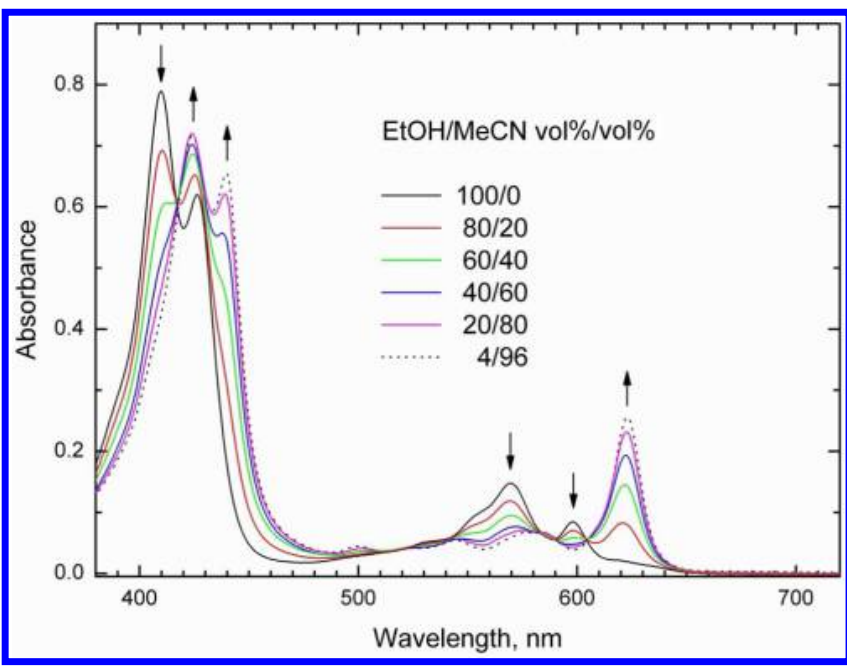

Figure 2. Ground state absorption spectra of 10-(4,6-dichloropyrimidin-5-yl)-5,15-dimesitylcorrole in $\mathrm{EtOH} / \mathrm{MeCN}$ mixtures. Arrows indicate the direction of spectral changes upon going from pure $\mathrm{EtOH}$ to $\mathrm{MeCN}\left(C_{\text {cor }}=7.5 \times 10^{-6} \mathrm{M}\right.$ for all samples $)$.

case under consideration, two forms are expected due to acidbase equilibria in the macrocyclic core), the titration should reveal the changes in the equilibrium between these two forms: the absorption spectrum of one form will decrease in intensity and that for the second form will increase, with distinct isosbestic points. The pattern of spectral changes found in the titration for $\mathrm{H}_{3} \mathrm{AB}_{2}$ obviously corresponds to the second scenario, i.e., the pyrimidinylcorrole has different forms in EtOH (the same form as in DCM, as indicated above ${ }^{11 \mathrm{c}}$ ) and $\mathrm{MeCN}$ (Figure 2). A decrease in the $\mathrm{EtOH} / \mathrm{MeCN}$ proportion leads to the appearance of species with a high intensity longwavelength transition band with a maximum at $\lambda=623 \mathrm{~nm}$. The long-wavelength bands of the two separate $\mathrm{NH}$ tautomers of the $\mathrm{Fb}$ corrole, with maxima at $\lambda=634$ and $598 \mathrm{~nm}$, gradually disappear. The absorption spectrum of the protonated corrole $\left(\mathrm{H}_{4} \mathrm{AB}_{2}^{+}\right)$is known to have a red-shifted longwavelength transition with a maximum at $\lambda=644 \mathrm{~nm}$ (see curve 3 in Figures 3 and 4 for the spectra of the protonated pyrimidinylcorrole in $\mathrm{MeCN}$ and $\mathrm{EtOH}$, respectively).,13 Therefore, one can expect that the observed spectrum is due to the formation of the deprotonated corrole species $\left(\mathrm{H}_{2} \mathrm{AB}_{2}^{-}\right)$ in $\mathrm{MeCN}$ (Figure 3, curve 1). This suggestion is in line with previously reported observations of the formation of deprotonated corrole species in polar solvents. ${ }^{6-10}$

The proposed explanation has been verified by spectrophotometric titration of the pyrimidinylcorrole solution in $\mathrm{MeCN}$ with sulfuric acid. It was found that the very first drop of diluted $\mathrm{H}_{2} \mathrm{SO}_{4}$ (leading to a total acid concentration in the solution of $2.0 \times 10^{-6} \mathrm{M}$ ) led to complete disappearance of the absorption spectrum with a characteristic band peaking at $\lambda=623 \mathrm{~nm}$. Indeed, the $\mathrm{Fb} \mathrm{H}_{3} \mathrm{AB}_{2}$ corrole spectrum with two well-defined long-wavelength bands with maxima at $\lambda=598$ and 635 appeared (Figure 3, curve 2). Distinct changes also took place for the Soret band: the spectrum of the $\mathrm{Fb}$ corrole, with maxima at $\lambda=409$ and $424 \mathrm{~nm}$, appeared instead of the band with maxima at $\lambda=424$ and $440 \mathrm{~nm}$. Proceeding to solutions with a higher acid concentration led to the formation of the protonated $\mathrm{H}_{4} \mathrm{AB}_{2}^{+}$corrole, possessing a well-defined long wavelength band peaking at $\lambda=639 \mathrm{~nm}$ (Figure 3, curve 3). In the Soret region, the protonated species has a maximum at $\lambda=$ $417 \mathrm{~nm}$, with a shoulder around $\lambda=429 \mathrm{~nm}$. It should be noted

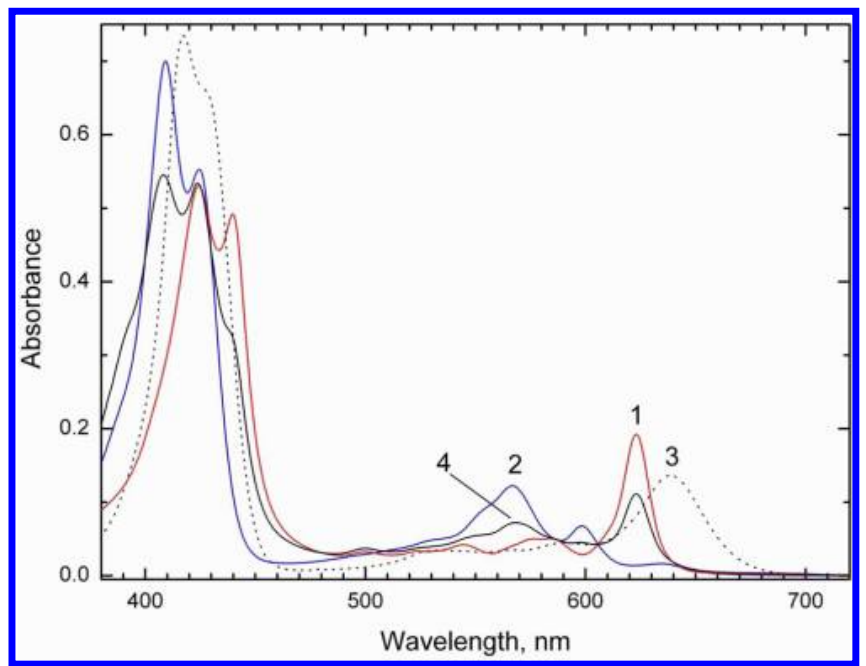

Figure 3. Ground state absorption spectra of 10-(4,6-dichloropyrimidin-5-yl)-5,15-dimesitylcorrole in: $1, \mathrm{MeCN}$ (red); $2, \mathrm{MeCN}+2.0$ $\times 10^{-6} \mathrm{M} \mathrm{H}_{2} \mathrm{SO}_{4}$ (blue); $3, \mathrm{MeCN}+1.4 \times 10^{-5} \mathrm{M} \mathrm{H}_{2} \mathrm{SO}_{4}$ (black dotted); 4, aged MeCN (black) ( $C_{\text {cor }}=6.6 \times 10^{-6} \mathrm{M}$ for all samples).

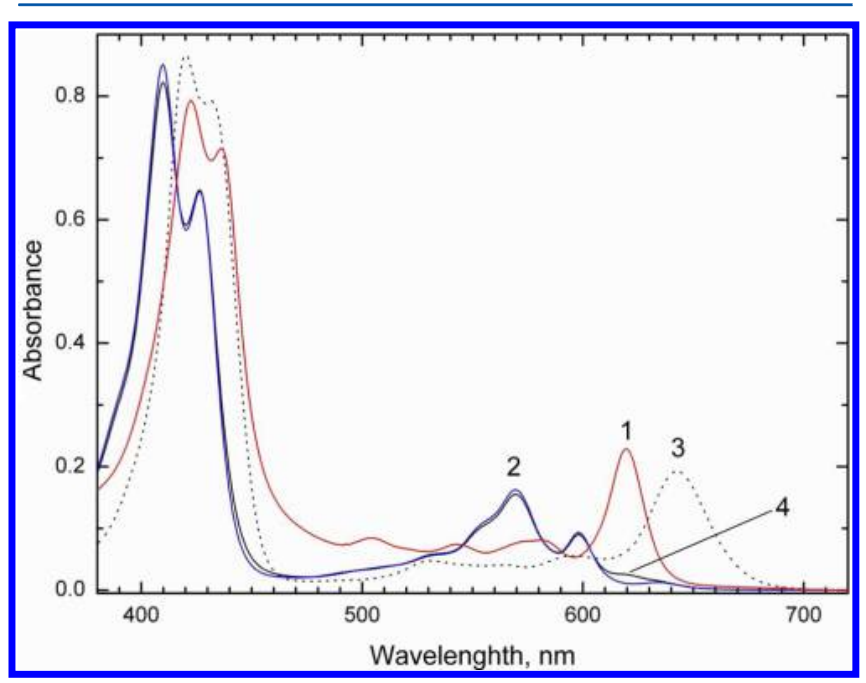

Figure 4. Ground state absorption spectra of 10-(4,6-dichloropyrimidin-5-yl)-5,15-dimesitylcorrole in: 1, EtOH + one drop of $1 \mathrm{M}$ $\mathrm{NaOH}$ (red); $2, \mathrm{EtOH}+3.3 \times 10^{-5} \mathrm{M} \mathrm{H}_{2} \mathrm{SO}_{4}$ (blue); $3, \mathrm{EtOH}+1.0$ $\times 10^{-4} \mathrm{M} \mathrm{H}_{2} \mathrm{SO}_{4}$ (black dotted); 4 , EtOH (black) $\left(C_{\text {cor }}=7.9 \times 10^{-6}\right.$ $\mathrm{M}$ for all samples).

that a set of isosbestic points was observed in the spectra upon transition from the $\mathrm{Fb} \mathrm{H}_{3} \mathrm{AB}_{2}$ corrole to the protonated $\mathrm{H}_{4} \mathrm{AB}_{2}{ }^{+}$corrole (not shown here, see ref 7 for details). Thus, one can conclude that the absorption spectrum observed for 10-(4,6-dichloropyrimidin-5-yl)-5,15-dimesitylcorrole in $\mathrm{MeCN}$ is due to the formation of the deprotonated $\mathrm{H}_{2} \mathrm{AB}_{2}{ }^{-}$ corrole species, and the spectral changes depicted in Figure 2 are really due to the $\mathrm{H}_{3} \mathrm{AB}_{2} \leftrightarrows \mathrm{H}_{2} \mathrm{AB}_{2}^{-}$equilibrium.

Additional proof for such an assignment was provided by the observed spectral changes for the $\mathrm{Fb}$ pyrimidinylcorrole in EtOH upon addition of one drop of $1 \mathrm{M} \mathrm{NaOH}$ solution (Figure 4, curve 1). Upon the addition of the base, the spectrum of the $\mathrm{Fb} \mathrm{H}_{3} \mathrm{AB}_{2}$ corrole transformed into the spectrum of the deprotonated $\mathrm{H}_{2} \mathrm{AB}_{2}{ }^{-}$corrole with a characteristic long wavelength band with a maximum at $\lambda=$ $620 \mathrm{~nm}$ and a bathochromic shift of the Soret band (band maxima at $\lambda=423$ and $439 \mathrm{~nm}$ ). It was evident that the 
spectrum was identical (with $2-3 \mathrm{~nm}$ solvent shifts) to that observed in $\mathrm{MeCN}$ (see Figures 2 and 3). Therefore, one can state that it is indeed the formation of the deprotonated $\mathrm{H}_{2} \mathrm{AB}_{2}{ }^{-}$corrole species that results in the dramatical spectral changes observed for the solution of 10-(4,6-dichloropyrimidin5-yl)-5,15-dimesitylcorrole in $\mathrm{MeCN}$, as compared to the spectral features of the $\mathrm{Fb} \mathrm{H}_{3} \mathrm{AB}_{2}$ corrole observed in $\mathrm{EtOH}$ and DCM.

One more noteworthy feature of the absorption spectrum measured in $\mathrm{EtOH}$ should be discussed. Upon the addition of acid, a decrease in absorbance in the spectral range 610-630 $\mathrm{nm}$ was observed at the very first titration steps (for which the total concentration of added acid in the solution was up to 3.3 $\left.\times 10^{-5} \mathrm{M}\right)$, whereas, at higher acid concentrations, an increase in the absorptivity was observed in this range (see Figure 4). ${ }^{7}$ This implies that two acid-base equilibria are involved in these spectral changes. At the initial stages, transformation of the minor proportion of deprotonated corrole molecules into their $\mathrm{Fb}$ form is observed. The decreasing absorbance belongs to the long wavelength band of the deprotonated $\mathrm{H}_{2} \mathrm{AB}_{2}{ }^{-}$corrole species, which exist in minor proportion in $\mathrm{EtOH}$ solution (Figure 4, curve 4). Addition of acid leads to the disappearance of the deprotonated species and the $\mathrm{Fb} \mathrm{H}_{3} \mathrm{AB}_{2}$ corrole becomes the only form of corrole in the ethanol solution with $3.3 \times 10^{-5}$ $\mathrm{M}$ of sulfuric acid (Figure 4, curve 2). Further increase in the acid concentration leads to the $\mathrm{Fb} \leftrightarrows$ monoprotonated corrole transition (Figure 4, curve 3). Thus, one can state that, upon dissolution in pure solvents, 10-(4,6-dichloropyrimidin-5-yl)5,15-dimesitylcorrole is able to exist either in the $\mathrm{Fb}$ or deprotonated form, or in both simultaneously, with the free base/deprotonated corrole ratio being the function of the solvent.

It was observed that the corrole solution in $\mathrm{MeCN}$ is not stable. Spectral changes due to aging of the solution/solvent were observed, leading to a less basic environment for the dissolved corrole molecules. As a result, part of the deprotonated $\mathrm{H}_{2} \mathrm{AB}_{2}{ }^{-}$corrole species undergo transformation into their $\mathrm{Fb}$ counterparts. An example of an aged corrole solution in $\mathrm{MeCN}$ is presented in Figure 3 (curve 4). One can see that the absorption spectrum of this aged corrole solution shares the features of both $\mathrm{Fb}$ and deprotonated species since they coexist in comparable proportions. As pointed out above, there are two ways of aging. Acetonitrile from freshly opened bottles allowed to obtain the pure spectrum of the deprotonated species, but old $\mathrm{MeCN}$ (taken from the stock) revealed a free base/deprotonated corrole mixture already upon dissolution (the $\mathrm{Fb}$ corrole solution has a khaki-like color, and the deprotonated corrole solution is bright green), with the proportion varying with the $\mathrm{MeCN}$ sampling used. However, solutions prepared with freshly opened MeCN revealed an observable amount of conversion of the deprotonated species in $\mathrm{Fb}$ species within a time period from several tens of minutes to a few days. We have assured ourselves that this spectral transformation was due to the microenvironmental changes upon aging and that there was no irreversible destruction of the corrole itself. When one drop of tetramethylammonium hydroxide $\left(\mathrm{N}\left(\mathrm{CH}_{3}\right)_{4} \mathrm{OH}\right)$ was added to the aged $\mathrm{MeCN}$ solution, where the majority of corrole was in the $\mathrm{Fb}$ form, the absorption spectrum of the deprotonated $\mathrm{H}_{2} \mathrm{AB}_{2}{ }^{-}$corrole was immediately restored.

The addition of small amounts of water to the $\mathrm{MeCN}$ solution was found to shift the acid-base equilibrium in the direction of the $\mathrm{Fb}$ species at the expense of the deprotonated ones. Taking as a starting point the arbitrarily aged $\mathrm{MeCN}$ sample, it was found that gradual addition of water led to complete conversion of the sample into the $\mathrm{Fb}$ form (Figure 5).

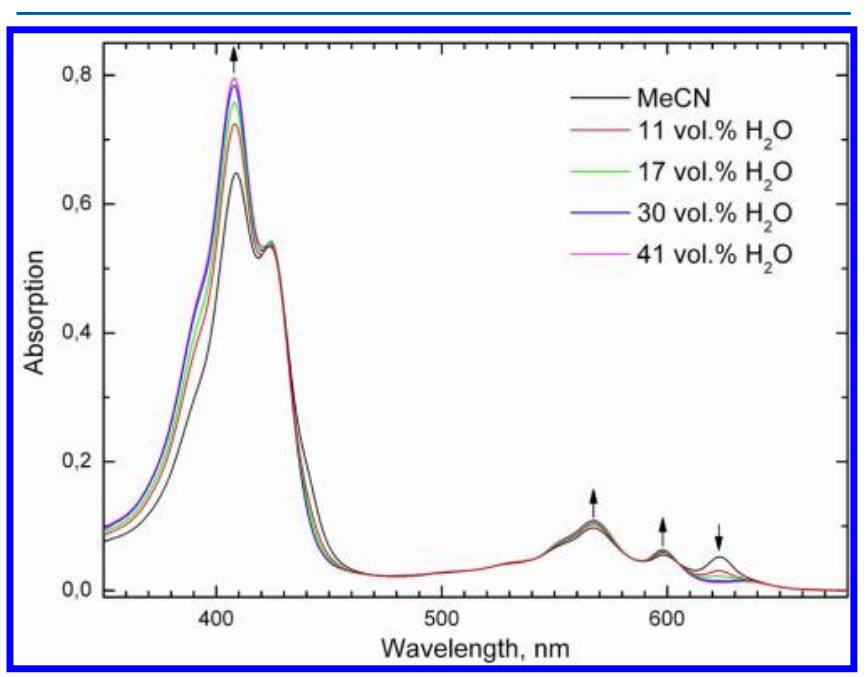

Figure 5. Ground state absorption spectra of 10-(4,6-dichloropyrimidin-5-yl)-5,15-dimesitylcorrole in aged $\mathrm{MeCN} / \mathrm{H}_{2} \mathrm{O}$ mixtures. Arrows indicate the direction of spectral changes upon progressive addition of water to aged $\mathrm{MeCN}\left(C_{\mathrm{cor}}=7.5 \times 10^{-6} \mathrm{M}\right.$ for all samples).

In the case of the aged solution, the amount of absorbed water is much smaller, and the bulk solvent properties are not significantly changed. However, water seems to replace acetonitrile molecules in the solvation shell of the corrole, leading to preferential stabilization of the $\mathrm{Fb}$ species. In the experiment described above (Figure 5), a much higher concentration of water was added, thus allowing a fast exchange to occur immediately after mixing. These results demonstrate that specific solvation seems to be also important for the solvent dependence of the spectral features of corroles, along with the bulk solvent properties, which are studied below. Besides the water-induced solvation shell changes, being in the first coordination sphere, the water molecules are also able to protonate the corrole core. Which of these two mechanisms has a major contribution remains an open question.

Solvent Dependence of the Free-Base $\leftrightarrows$ Deprotonated Corrole Equilibrium. The ground state absorption spectra of 10-(4,6-dichloropyrimidin-5-yl)-5,15-dimesitylcorrole have been measured in 15 solvents differing in their physicochemical properties (Table 1). The $\mathrm{Fb} \mathrm{H}_{3} \mathrm{AB}_{2}$ corrole has been observed in most of the solvents studied, whereas the deprotonated $\mathrm{H}_{2} \mathrm{AB}_{2}{ }^{-}$corrole species has been observed in five of them, being the only compound in $\mathrm{MeCN}$, acetone, and DMSO. In DMF, the majority of the molecules were found to be deprotonated, but a considerable amount of corrole was also in the neutral $\mathrm{Fb}$ form. In $\mathrm{EtOH}$ (as already pointed out above), a very minor proportion of deprotonated $\mathrm{H}_{2} \mathrm{AB}_{2}{ }^{-}$ corrole was identified.

The $\mathrm{Fb}$ species did not reveal any clear solvatochromic effects in the solvents studied. The maxima of the $0-0$ electronic transitions for the $\mathrm{T} 1$ and $\mathrm{T} 2$ tautomers lie at 631$636 \mathrm{~nm}$ and 597-600 nm, respectively (i.e., the solventinduced differences in state energies are $\sim 100$ and $135 \mathrm{~cm}^{-1}$, respectively). No correlation was found upon analysis of these spectral shifts as a function of solvent dielectric constant, polarizability, polarity $E_{\mathrm{T}}^{\mathrm{N}}$, hydrogen bond acceptor strength $\beta$, or Lippert $\Delta f$ function. The experimental points are randomly 
Table 1. Free-Base $\leftrightarrows$ Deprotonated Pyrimidinylcorrole Equilibrium As a Function of Solvent Properties ${ }^{a}$

\begin{tabular}{|c|c|c|c|c|c|c|c|}
\hline solvent & $-\Delta H_{0}(\mathrm{~kJ} / \mathrm{mol})$ & $\mathrm{DN}$ & Swain basity & $\beta$ & $E_{\mathrm{T}}^{\mathrm{N}}$ & major contribution & minor contribution \\
\hline dichloromethane & & 1.00 & 0.80 & 0.10 & 0.31 & $\mathrm{Fb}$ & \\
\hline 1,2-dichlorobenzene & & & & 0.03 & 0.23 & $\mathrm{Fb}$ & \\
\hline benzene & 4.3 & 0.10 & 0.59 & 0.10 & 0.11 & $\mathrm{Fb}$ & \\
\hline $\mathrm{MeCN}$ & 10.4 & 14.1 & 0.86 & 0.40 & 0.46 & deprotonated & \\
\hline acetone & & 17.0 & 0.81 & 0.43 & 0.35 & deprotonated & \\
\hline 1,4-dioxane & 10.8 & 14.3 & 0.67 & 0.37 & 0.16 & $\mathrm{Fb}$ & \\
\hline ethyl acetate & & 17.1 & 0.59 & 0.45 & 0.23 & $\mathrm{Fb}$ & \\
\hline THF & 12.7 & 20.0 & 0.67 & 0.55 & 0.21 & $\mathrm{Fb}$ & \\
\hline 2-Me-THF & & & & 0.52 & & $\mathrm{Fb}$ & \\
\hline pyridine & 15.0 & 33.1 & 0.96 & 0.64 & 0.30 & $\mathrm{Fb}$ & \\
\hline $\mathrm{MeOH}$ & & 19.0 & 0.50 & 0.66 & 0.76 & $\mathrm{Fb}$ & \\
\hline DMF & & 26.6 & 0.93 & 0.69 & 0.40 & deprotonated & $\mathrm{Fb}$ \\
\hline DMSO & 16.0 & 29.8 & 1.08 & 0.76 & 0.44 & deprotonated & \\
\hline $\mathrm{EtOH}$ & & 19.2 & 0.45 & 0.75 & 0.65 & $\mathrm{Fb}$ & deprotonated \\
\hline EtOD & & & & & 0.64 & $\mathrm{Fb}$ & \\
\hline
\end{tabular}

${ }^{a} \Delta H_{0}$ is the hydrogen-bonding affinity to pyrrole; ${ }^{14} \mathrm{DN}$ is the Gutmann donor number; ${ }^{15}$ the Swain basity is the cation solvating power of a solvent; ${ }^{16}$ Kamlet-Taft hydrogen bond acceptor strength $\beta ;{ }^{17} E_{\mathrm{T}}{ }^{\mathrm{N}}$ is the solvent polarity on the Dimroth-Reichardt empirical scale. ${ }^{18}$

scattered in all plots. The difference in the position of the $0-0$ transition maximum for the deprotonated species is about 180 $\mathrm{cm}^{-1}$, but the data again did not show any correlation with the above-mentioned solvent parameters. Therefore, we are forced to conclude that solvatochromism has no significant contribution to the observed solvent-induced spectral changes of the studied $\mathrm{AB}_{2}$-pyrimidinylcorrole.

Starting the analysis of the solvent dependence, it should be stressed that there is no single solvent parameter correlating with the corrole form existing in the given solutions according to our experimental observations (Table 1). It is worthy to note that, in pyridine, the most basic solvent within the series, no deprotonation was observed. The Gutmann donor number DN is a measure of the strength of a solvent as a Lewis base, but there was no correlation found with these values (Table 1). The same situation was obtained for the Kamlet-Taft hydrogen bond acceptor strength $\beta$ (Table 1 ) and polarizability $\pi^{*}$ (not shown since it is essentially the same as for $\beta$ ). The solvents for which the deprotonated corroles were observed, can be divided in two groups (acetone, $\mathrm{MeCN}$ and DMF, DMSO) with strongly different $\beta$ parameters. This means that either at least one additional parameter should be considered or specific interactions should be involved in some cases to explain the observed pattern of spectral changes. Indeed, in addition to the basicity, the solvent should provide a high polarity to deprotonate the corrole molecule since only solvents with high polarity are able to solvate charged species efficiently. ${ }^{18}$ These two features are combined in some extent in the Swain empirical "acity" and "basity" parameters, representing anion and cation solvating power of a solvent, respectively, ${ }^{16}$ but there was no correlation found in this case either (Table 1). However, all the solvents for which the deprotonated $\mathrm{H}_{2} \mathrm{AB}_{2}{ }^{-}$ corrole species have been observed keep together now, i.e., have closely matching Swain basity parameter values. Pyridine and DCM, for which the $\mathrm{Fb}$ corrole was observed only, have, however, a Swain basity within the range where the deprotonating solvents were grouped. EtOH stays far from this Swain basity range, being separated by several solvents with intermediate values. It is worthwhile to note that, in the basicity (Bp value) scale of Fawcett, ${ }^{19} \mathrm{EtOH}$ also finds itself in the wrong place, but the relatively small number of $\mathrm{Bp}$ values available to date unfortunately does not allow analyzing the correlation in depth.

To evaluate the role of polarity in the observed spectral changes, we have also carried out an analysis of the correlation with the empirical solvent polarity scale introduced by Dimroth and Reichardt (taken in the normalized dimensionless $E_{\mathrm{T}}{ }^{\mathrm{N}}$ from ref 18), which gave also similar results. The $\mathrm{Fb} \mathrm{H}_{3} \mathrm{AB}_{2}$ corrole has been observed in the low-polar solvents (up to $E_{\mathrm{T}}{ }^{\mathrm{N}}$ $\approx 0.3-0.35$ ), whereas the deprotonated $\mathrm{H}_{2} \mathrm{AB}_{2}{ }^{-}$corrole species was observed for $E_{\mathrm{T}}{ }^{\mathrm{N}} \approx 0.35-0.46$. The alcohols $(\mathrm{MeOH}$ and $\mathrm{EtOH}$ ) with $E_{\mathrm{T}}{ }^{\mathrm{N}}$ values as high as 0.76 and 0.65 were, however, out of correlation again, pointing toward some kind of specific interactions in the solutions.

In general, the solvents analyzed can be classified in three groups, nonpolar, polar aprotic, and polar protic solvents, with the largest one being the group of polar aprotic solvents (DCM, THF, 2-Me-THF, ethyl acetate, acetone, DMF, MeCN, DMSO, and pyridine). When analyzing the spectral data within this group, one can conclude that an increase in polarity (taken as either the bulk dielectric constant or dipole moment of the solvent molecule) leads to switching from the $\mathrm{Fb}$ to the deprotonated corrole. However, again no correlation was seen between the 0-0 transition maxima and these solvent properties.

We have mentioned above the early hypothesis on the specific intermolecular hydrogen bonding of pyrrolic hydrogen atoms with solvent molecules, 5 with pyrrole being a hydrogenbond donor and the solvent molecules being hydrogen-bond acceptors. In a recent paper, specific hydrogen-bond basicity, treated as the thermodynamic tendency of a given solvent molecule to act as a hydrogen-bond acceptor, has been studied. $^{14}$ The hydrogen-bond basicity scale has been constructed from the equilibrium constants for hydrogenbond complex formation for a series of solvents acting as hydrogen-bond acceptors with several reference compounds acting as hydrogen-bond donors. One of these hydrogen-bond donors was pyrrole, and we have examined the relationship between the hydrogen-bond affinity to pyrrole and the observed spectra of the pyrimidinylcorrole $\left(-\Delta H_{0}\right.$ values in Table 1). The data were, however, too scattered, and no correlation was seen, i.e., no relationship between the measured absorption spectra and the ability of a given solvent to form a 
hydrogen bond with the pyrrole hydrogen was found. Therefore, one can suggest that hydrogen-bonding as an alternative explanation of the solvent-dependent spectral properties of pyrimidinylcorroles is unlikely.

Finally, we need to discuss the specific features of the corrole itself, which can also contribute to the observed solventdependent properties. First of all, the asymmetry of the corrole macrocycle needs to be taken into account and the phenomenon of possible intramolecular hydrogen bonding in the macrocyclic core. ${ }^{20}$ There are three pyrrolic protons in the core and any of them can dissociate under basic conditions (after the proton removal, the two remaining protons arrange to adopt a stable trans-configuration, which is characteristic for tetrapyrrolic macrocycles having two core hydrogens, as for the deprotonated $\mathrm{H}_{2} \mathrm{AB}_{2}{ }^{-}$corrole $\left.{ }^{21}\right)$. Thus, all of this could result in a different acidity of the three $\mathrm{NH}$ protons. Because of the specificity of the corrole solvation in a given solvent, different pyrroles (i.e., having different $\mathrm{p} K_{\mathrm{a}} \mathrm{s}$ ) could be involved in the formation of the deprotonated species. The role of the corrole $\mathrm{NH}$ tautomers should also be considered. As we have shown recently, ${ }^{7}$ the basicity of the two pyrimidinylcorrole $\mathrm{NH}$ tautomers is different. Therefore, it is reasonable to expect that the same is true for the acidity: the two corrole $\mathrm{NH}$ tautomers have different acidity, and evidence for this assumption is provided in the next section. One can suggest that, in the deprotonating solvents, the solvation leads to (preferential) stabilization of the more acidic $\mathrm{NH}$ tautomer. Thus, from this hypothesis, an elegant explanation of the deprotonation results can be derived: stabilization of the NH tautomer with enhanced acidity produces the deprotonated species immediately upon dissolving the corrole in this solvent, i.e., the deprotonated $\mathrm{H}_{2} \mathrm{AB}_{2}{ }^{-}$corrole is observed instead of another $\mathrm{NH}$ tautomer of the $\mathrm{Fb} \mathrm{H}_{3} \mathrm{AB}_{2}$ corrole. If this explanation is valid, indeed, we are in fact dealing with a coupled $\mathrm{NH}$ tautomer-deprotonation equilibrium, involving three types of species in solution. This hypothesis is currently being examined for a series of $A_{2}, A_{2} B$, and $\mathrm{A}_{3}$ meso-pyrimidinylcorroles.

Fluorescence Properties of the Deprotonated Pyrimidinylcorrole. The fluorescence spectra of 10-(4,6-dichloropyrimidin-5-yl)-5,15-dimesitylcorrole were measured in mixed $\mathrm{EtOH} / \mathrm{MeCN}$ solutions (Figure 6). One can see that, upon going from pure $\mathrm{EtOH}$ to $\mathrm{MeCN}$, the fluorescence intensity decreases, but up to the last titration step, the spectrum retains its initial shape, and only at the very end does the shape of the spectrum change, due to the substantial difference in the fluorescence quantum yields $\left(\Phi_{\mathrm{fl}}\right)$ for the $\mathrm{Fb}$ and deprotonated corrole molecules. Upon increase in the proportion of the deprotonated $\mathrm{H}_{2} \mathrm{AB}_{2}{ }^{-}$species, the majority of the fluorescence is still coming from the $\mathrm{Fb}$ form, and only when the $\mathrm{Fb}$ molecules disappear, can the fluorescence spectrum of the deprotonated $\mathrm{H}_{2} \mathrm{AB}_{2}{ }^{-}$corrole be seen. However, a different rate of decrease in the intensities of the fluorescence bands belonging to the long wavelength $\mathrm{T} 1$ and short wavelength $\mathrm{T} 2$ $\mathrm{Fb}$ corrole tautomers (see ref 22 for the assignment) is observed (Figure 7). According to our developed model describing the interaction of the two $\mathrm{NH}$ tautomers with a titrant, ${ }^{7}$ the relationship between the concentrations of the two $\mathrm{NH}$ tautomers during the course of the titration is nonlinear if the rates of product formation for the two $\mathrm{NH}$ tautomers differ by a factor $\chi$ :

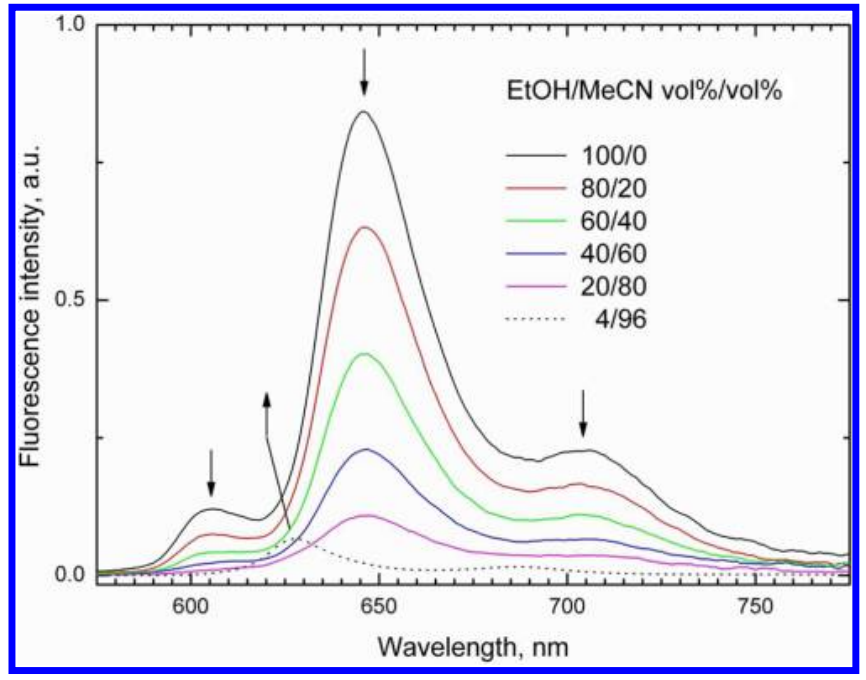

Figure 6. Absorbance-normalized fluorescence spectra of 10-(4,6dichloropyrimidin-5-yl)-5,15-dimesitylcorrole in $\mathrm{EtOH} / \mathrm{MeCN}$ mixtures $\left(\lambda_{\mathrm{exc}}=475 \mathrm{~nm}\right)$. Arrows indicate the direction of spectral changes upon going from pure $\mathrm{EtOH}$ to $\mathrm{MeCN}\left(C_{\text {cor }}=7.5 \times 10^{-6} \mathrm{M}\right.$ for all samples).

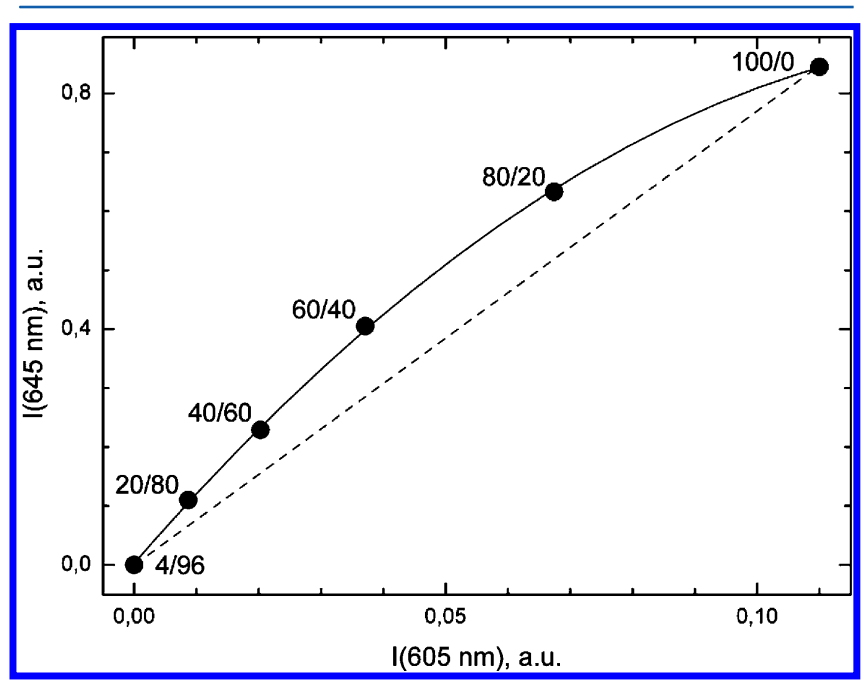

Figure 7. Peak fluorescence intensity of the long wavelength $\mathrm{NH}$ tautomer (at $645 \mathrm{~nm}$ ) as a function of the peak fluorescence intensity of the short wavelength $\mathrm{NH}$ tautomer (at $605 \mathrm{~nm}$ ), measured in $\mathrm{EtOH} / \mathrm{MeCN}$ mixtures (the indicated percentages correspond to those in Figures 2 and 6). The dashed line indicates the expected dependence in case the two deprotonation rates are equal.

$$
\frac{\mathrm{T} 1}{\mathrm{~T} 1_{0}}=\left(\frac{\mathrm{T} 2}{\mathrm{~T} 2_{0}}\right)^{\chi} \text { and } \frac{\mathrm{T} 2}{\mathrm{~T} 2_{0}}=\left(\frac{\mathrm{T} 1}{\mathrm{~T} 1_{0}}\right)^{1 / \chi}
$$

where the ratios $\mathrm{T} 1 / \mathrm{T} 1_{0}$ and $\mathrm{T} 2 / \mathrm{T} 2_{0}$ represent the residual ratios of tautomers $\mathrm{T} 1$ and $\mathrm{T} 2$ at each titration step. The values of the peak fluorescence intensities (taken at the wavelengths of the corresponding $0-0$ transition bands) are proportional to the $\mathrm{NH}$ tautomer concentrations in solution during the EtOH/ $\mathrm{MeCN}$ titration:

$$
\mathrm{I}(\mathrm{T} 1)=\alpha \mathrm{I}(\mathrm{T} 2)^{\chi}
$$

where $\alpha$ is a constant introduced to take into account the difference in the fluorescence quantum yields of the two $\mathrm{NH}$ tautomers. Therefore, the convex shape of the dependence observed (Figure 7) unambiguously points out to that the 
deprotonation rate of the short wavelength $\mathrm{T} 2$ tautomer is higher, i.e., the $\mathrm{T} 2$ tautomer has a higher acidity as compared to that of the T1 tautomer.

The Stokes shift between the maxima of the $0-0$ transition in the absorption and fluorescence spectra of the deprotonated $\mathrm{H}_{2} \mathrm{AB}_{2}^{-}$corrole is $115 \mathrm{~cm}^{-1}$. This value is about two times lower than the Stokes shift measured for the $\mathrm{Fb}$ corrole (221 and $257 \mathrm{~cm}^{-1}$ for the two $\mathrm{NH}$ tautomers ${ }^{7}$ ), indicating the absence of substantial structural rearrangements in the excited state.

A fluorescence quantum yield $\Phi_{\mathrm{fl}}$ as high as 0.076 has been measured for the $\mathrm{Fb} \mathrm{H} \mathrm{AB}_{2}$ corrole in $\mathrm{EtOH}$. This value is in a good agreement with the value $\Phi_{\mathrm{fl}}=0.066$ recently measured in DCM. ${ }^{11 \mathrm{c}}$ The deprotonated $\mathrm{H}_{2} \mathrm{AB}_{2}{ }^{-}$corrole fluorescence is very weak with a $\Phi_{\mathrm{fl}}=0.004$ measured in the mixture EtOH/ $\mathrm{MeCN} 4 / 96$ (by volume). Early publications have reported on the increase in the fluorescence quantum yield upon the formation of deprotonated corrole species. ${ }^{6,9}$ Our findings indicate that this is not always the case. The decrease in the overall fluorescence quantum yield measured during the course of the titration is reciprocal to the growing absorbance of the long wavelength $0-0$ transition of the deprotonated $\mathrm{H}_{2} \mathrm{AB}_{2}{ }^{-}$ corrole at $\lambda=623 \mathrm{~nm}$ (Figure 8). This observation allows an unambiguous assignment of the fluorescence quantum yield decrease to the formation of the deprotonated species.

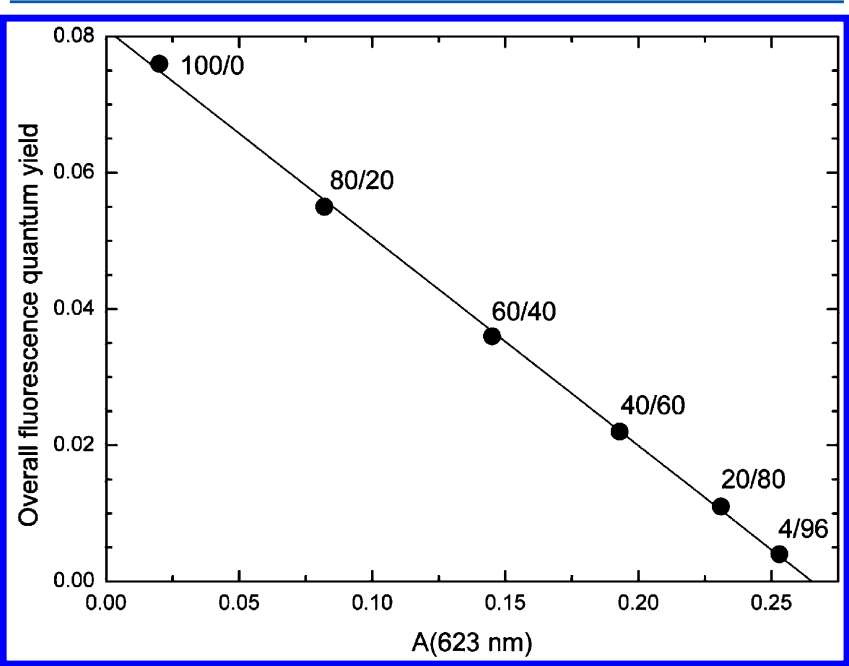

Figure 8. Overall fluorescence quantum yields of 10-(4,6-dichloropyrimidin-5-yl)-5,15-dimesitylcorrole in $\mathrm{EtOH} / \mathrm{MeCN}$ mixtures (the indicated percentages correspond to those in Figures 2 and 6) as a function of the absorbance at $623 \mathrm{~nm}$. The solid line represents the linear fit of the experimental data.

The main proof for this assignment comes from the fluorescence excitation spectra, which have been measured for the $\mathrm{Fb} \mathrm{H} \mathrm{HB}_{2}$, deprotonated $\mathrm{H}_{2} \mathrm{AB}_{2}{ }^{-}$, and protonated $\mathrm{H}_{4} \mathrm{AB}_{2}{ }^{+}$ forms of the pyrimidinylcorrole (Figure 9). One can see that the fluorescence excitation spectra correspond very well with the absorption spectra of these forms (see Figures 3 and 4). The fluorescence spectra of all three forms of 10-(4,6dichloropyrimidin-5-yl)-5,15-dimesitylcorrole are shown in Figure 10. The wavelength of the fluorescence maximum increases in the series $\mathrm{H}_{2} \mathrm{AB}_{2}^{-}>\mathrm{H}_{3} \mathrm{AB}_{2}>\mathrm{H}_{4} \mathrm{AB}_{2}{ }^{+}$. All species have their own distinct shape of the fluorescence spectrum and are also clearly distinguished by their fluorescence quantum yields. The value $\Phi_{\mathrm{fl}}=0.004\left(\mathrm{H}_{2} \mathrm{AB}_{2}{ }^{-}\right)$is the minimal one

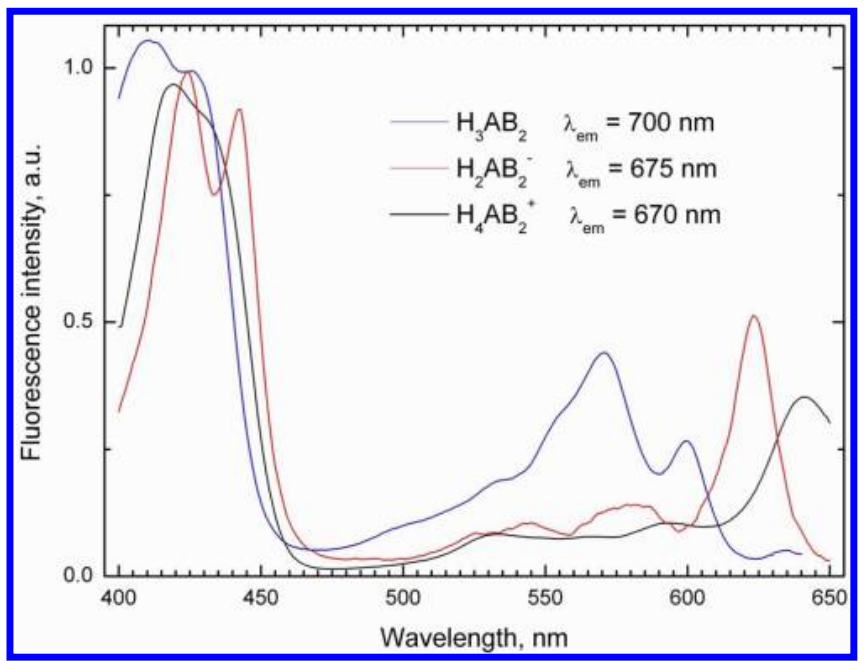

Figure 9. Fluorescence excitation spectra of the free-base (in $\mathrm{MeCN}+$ $2.0 \times 10^{-6} \mathrm{M} \mathrm{H}_{2} \mathrm{SO}_{4}$ ), deprotonated (in $\mathrm{MeCN}$ ), and protonated (in $\mathrm{MeCN}+1.4 \times 10^{-5} \mathrm{M} \mathrm{H}_{2} \mathrm{SO}_{4}$ ) forms of 10-(4,6-dichloropyrimidin-5yl)-5,15-dimesitylcorrole.

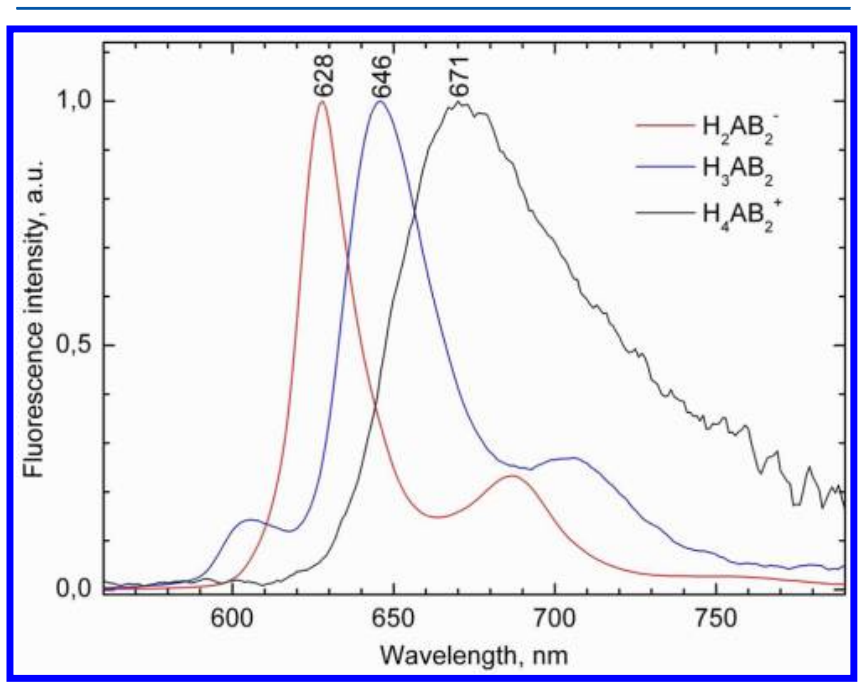

Figure 10. Fluorescence spectra of the free-base (in $\mathrm{MeCN}+2.0 \times$ $10^{-6} \mathrm{M} \mathrm{H}_{2} \mathrm{SO}_{4}$ ), deprotonated (in $\mathrm{MeCN}$ ), and protonated (in $\mathrm{MeCN}$ $+1.4 \times 10^{-5} \mathrm{M} \mathrm{H}_{2} \mathrm{SO}_{4}$ ) forms of 10-(4,6-dichloropyrimidin-5-yl)5,15-dimesitylcorrole. All spectra were normalized for maximum intensity.

among the three species. An intermediate value of $\Phi_{\mathrm{fl}}=0.037$ was measured for the protonated $\mathrm{H}_{4} \mathrm{AB}_{2}{ }^{+}$form in $\mathrm{MeCN}$, and the $\mathrm{Fb} \mathrm{H} \mathrm{H}_{3} \mathrm{AB}_{2}$ corrole has the highest $\Phi_{\mathrm{fl}}$ value.

\section{CONCLUSIONS}

The solvent dependence of the absorption and emission spectra of 10-(4,6-dichloropyrimidin-5-yl)-5,15-dimesitylcorrole has been studied in a series of solvents. It was shown that dramatic changes in the absorption spectrum in $\mathrm{MeCN}$, acetone, $\mathrm{DMF}$, and DMSO are due to the formation of deprotonated $\mathrm{H}_{2} \mathrm{AB}_{2}{ }^{-}$ corrole species. The relationship of the formation of deprotonated species with physicochemical solvent properties is discussed in detail, concluding that there is no observable correlation with a single solvent parameter and that either multiparameter correlations or specific interactions between the corrole and the solvent molecules should be considered. The possible contribution of the two corrole $\mathrm{NH}$ tautomers to this 
issue has also been discussed. The fluorescence properties of the deprotonated pyrimidinylcorrole have been characterized as well. In contrast with previous observations made for other corrole derivatives, it was found that the fluorescence quantum yield of the deprotonated form decreases as compared to the free-base species.

The obtained results demonstrate that the pronounced solvent-dependent spectral changes for corroles probably originate from several factors. In addition to the contribution due to $\mathrm{NH}$ tautomerization, ${ }^{7,22}$ we have shown in this report that, in several cases, the free base $\leftrightarrows$ deprotonated corrole equilibrium can be dominant. This means that, for future analysis of the photophysical properties of free-base corroles, the contribution of the separate corrole $\mathrm{NH}$ tautomers and possible deprotonation should generally be taken into account.

\section{AUTHOR INFORMATION}

\section{Corresponding Author}

*(M.K.) Tel: (+375) 17284 1563. Fax: (+375) 172840679. E-mail: kruk@imaph.bas-net. (W.M.) Tel: (+32) 11268312. Fax: (+32) 11 268299. E-mail: wouter.maes@uhasselt.be.

\section{Author Contributions}

The manuscript was written through contributions of all authors. All authors have given approval to the final version of the manuscript.

\section{Notes}

The authors declare no competing financial interest.

\section{ACKNOWLEDGMENTS}

This work has been carried out with financial support from FP7 project DphotoD-PEOPLE-IRSES-GA-2009-247260. The State Program of Scientific Research "Convergence" of the Republic of Belarus (projects 3.1.03 and 3.4.01) is acknowledged by M.K., A.S, and V.S. W.M., T.H.N., and W.D. thank the FWO (Fund for Scientific Research, Flanders), the KU Leuven, and the Ministerie voor Wetenschapsbeleid for continuing financial support. T.H.N. further acknowledges the IWT (Institute for the Promotion of Innovation through Science and Technology in Flanders) and the Alexander von Humboldt Foundation for a doctoral and postdoctoral fellowship, respectively.

\section{REFERENCES}

(1) Reviews on corrole applications: (a) Aviv, I.; Gross, Z. Chem. Commun. 2007, 1987-1999. (b) Flamigni, L.; Gryko, D. T. Chem. Soc. Rev. 2009, 38, 1635-1646. (c) Aviv-Harel, I.; Gross, Z. Chem.-Eur. J. 2009, 15, 8382-8394. (d) Aviv-Harel, I.; Gross, Z. Coord. Chem. Rev. 2011, 255, 717-736.

(2) (a) Barbe, J.-M.; Canard, G.; Brandès, S.; Guilard, R. Chem.-Eur. J. 2007, 13, 2118-2129. (b) Mahammed, A.; Gross, Z. Chem. Commun. 2010, 7040-7042. (c) Kupershmidt, L.; Okun, Z.; Amit, T.; Mandel, S.; Saltsman, I.; Mahammed, A.; Bar-Am, O.; Gross, Z.; Youdim, M. B. H. J. Neurochem. 2010, 113, 363-373. (d) Abu-Omar, M. M. Dalton Trans. 2011, 40, 3435-3444. (e) Suranjana Bose, S.; Pariyar, A.; Biswas, A. N.; Das, P.; Bandyopadhyay, P. Catal. Commun. 2011, 12, 446-449. (f) Dogutan, D. K.; McGuire, R.; Nocera, D. G. J. Am. Chem. Soc. 2011, 133, 9178-9180. (g) Aviv-Harel, I.; Gross, Z. Coord. Chem. Rev. 2011, 255, 717-736. (h) Flamigni, L.; Ciuciu, A. I.; Langhals, H.; Böck, B.; Gryko, D. T. Chem. Asian J. 2012, 7, 582-592. (3) Johnson, A. W.; Kay, I. T. J. Chem. Soc. 1965, 1620-1629.

(4) Reviews on (synthetic) corrole chemistry: (a) Gryko, D. T. Eur. J. Org. Chem. 2002, 1735-1743. (b) Gryko, D. T.; Fox, J. P.; Goldberg, P. J. Porphyrins Phthalocyanines 2004, 8, 1091-1105. (c) Ghosh, A. Angew. Chem., Int. Ed. 2004, 43, 1918-1931. (d) Nardis, S.; Monti, D.;
Paolesse, R. Mini-Rev. Org. Chem. 2005, 2, 355-374. (e) Paolesse, R. Synlett 2008, 2215-2230. (f) Gryko, D. T. J. Porphyrins Phthalocyanines 2008, 12, 906-917. (g) Lemon, C. M.; Brothers, P. J. J. Porphyrins Phthalocyanines 2011, 15, 809-834.

(5) Ding, T.; Aleman, E. A.; Modarelli, D. A.; Ziegler, C. J. J. Phys. Chem. A 2005, 109, 7411-7417.

(6) Mahammed, A.; Weaver, J. J.; Gray, H. B.; Abdelas, M.; Gross, Z. Tetrahedron Lett. 2003, 44, 2077-2079.

(7) Ivanova, Y. B.; Savva, V. A.; Mamardashvili, N. Z.; Starukhin, A. S.; Ngo, T. H.; Dehaen, W.; Maes, W.; Kruk, M. M. J. Phys. Chem. A. 2012, DOI: $10.1021 /$ jp305325e, companion article.

(8) (a) Gross, Z.; Galili, N.; Saltsman, I. Angew. Chem., Int. Ed. 1999, 38, 1427-1429. (b) Paolesse, R.; Jaquinod, L.; Nurco, D. J.; Mini, S.; Sagone, F.; Boschi, T.; Smith, K. M. Chem. Commun. 1999, 13071308. (c) Simkovich, L.; Goldberg, I.; Gross, Z. J. Inorg. Biochem. 2000, 80, 235-238.

(9) Bendix, J.; Dmochowski, I. J.; Gray, H. B.; Mahammed, A.; Simkovich, L.; Gross, Z. Angew. Chem., Int. Ed. 2000, 39, 4048-4051.

(10) (a) Shen, J.; Shao, J.; Ou, Z.; E, W.; Koszarna, B.; Gryko, D. T.; Kadish, K. M. Inorg. Chem. 2006, 45, 2251-2265. (b) Shen, J.; Ou, Z.; Shao, J.; Galezowski, M.; Gryko, D. T.; Kadish, K. M. J. Porphyrins Phthalocyanines 2007, 11, 269-276. (c) Ou, Z.; Sun, H.; Zhu, W.; Da, Z; Kadish, K. M. J. Porphyrins Phthalocyanines 2008, 12, 1-10.

(11) (a) Maes, W.; Ngo, T. H.; Vanderhaeghen, J.; Dehaen, W. Org. Lett. 2007, 9, 3165-3168. (b) Ngo, T. H.; Van Rossom, W.; Dehaen, W.; Maes, W. Org. Biomol. Chem. 2009, 7, 439-443. (c) Ngo, T. H.; Puntoriero, F.; Nastasi, F.; Robeyns, K.; Van Meervelt, L.; Campagna, S.; Dehaen, W.; Maes, W. Chem.-Eur. J. 2010, 16, 5691-5705. (d) Ngo, T. H.; Nastasi, F.; Puntoriero, F.; Campagna, S.; Dehaen, W.; Maes, W. J. Org. Chem. 2010, 75, 2127-2130. (e) Nastasi, F.; Campagna, S.; Ngo, T. H.; Dehaen, W.; Maes, W.; Kruk, M. Photochem. Photobiol. Sci. 2011, 10, 143-150. (f) Ngo, T. H.; Nastasi, F.; Puntoriero, F.; Campagna, S.; Dehaen, W.; Maes, W. Eur. J. Org. Chem. 2012, 28, 5605-5617.

(12) Knyukshto, V.; Zenkevich, E.; Sagun, E.; Shulga, A.; Bachilo, S. Chem. Phys. Lett. 1998, 297, 97-108.

(13) Ou, Z.; Shen, J.; Shao, J.; E, W.; Galezowski, M.; Gryko, D. T.; Kadish, K. M. Inorg. Chem. 2007, 46, 2775-2786.

(14) Laurence, C.; Graton, J.; Berthelot, M.; Besseau, F.; Le Questel, J.-Y.; Luçon, M.; Ouvrard, C.; Planchat, A.; Renault, E. J. Org. Chem. 2010, 75, 4105-4123.

(15) Gutmann, V. Electrochim. Acta 1976, 21, 661-670.

(16) Swain, C. G.; Swain, M. S.; Powell, A. L.; Alunni, S. J. Am. Chem. Soc. 1983, 105, 502-513.

(17) (a) Kamlet, M. J.; Taft, R. W. J. Am. Chem. Soc. 1976, 98, 377383. (b) Krygowski, T. M.; Milczarek, E.; Wrona, P. K. J. Chem. Soc., Perkin Trans. 2 1980, 1563-1568.

(18) (a) Reichardt, C.; Welton, T. Solvents and Solvent Effects in Organic Chemistry, 4th ed.; Wiley-VCH: Weinheim, Germany, 2010.

(b) Reichardt, C. Chem. Rev. 1994, 94, 2319-2358.

(19) Fawcett, W. R. J. Phys. Chem. 1993, 97, 9540-9546.

(20) Balazs, Y. S.; Saltsman, I.; Mahammed, A.; Tkachenko, E.; Golubkov, G.; Levine, J.; Gross, Z. Magn. Reson. Chem. 2004, 42, 624635 .

(21) (a) Ghosh, A.; Jynge, K. Chem.-Eur. J. 1997, 3, 823-833. (b) Ghosh, A. Acc. Chem. Res. 1998, 31, 189-198.

(22) Kruk, M. M.; Ngo, T. H.; Verstappen, P.; Starukhin, A. S.; Hofkens, J.; Dehaen, W.; Maes, W. J. Phys. Chem. A. 2012, DOI: $10.1021 /$ jp305326x, companion article. 